\title{
HUMAN BODY-GESTURE CAPACITY: THE TENSE - LAX DISTINCTION: A PRELIMINARY OUTLINE OF RESEARCH WORK
}

\author{
JOANNA PUPPEL
}

\begin{abstract}
In phonology, the terms 'tenseness' (tensing) and 'laxness' (laxing) are an important pair pertaining to the distinctive features of vowels. A similar dichotomy, 'tenseness' - 'laxness', can also be observed in the body-gesture (B-G) behaviors.

On the basis of this distinction, the author of the article proposes to make a division between two bodygesture cultures, namely: the 'lax B-G cultures', and the 'tense B-G cultures', respectively.

Additionally, the author constructs two working hypotheses. Namely:

Hypothesis no. 1 (H1):

(H1a): The laxer the B-G system is, the less ritual (and more casual) a given communication act happens to be. (H1b): The relationship "lax body posture + lax gesture" correlates with full spoken, profane (non-ritual) communication potential.

Hypothesis no. 2 (H2):

(H2a): The tenser the B-G system is, the more ritual a given communication act happens to be.

(H2b): The relationship "tense body posture + tense gesture" correlates with full spoken, ritual (nonprofane) communication potential.
\end{abstract}

Key words: human body, gesture, tense and lax body-gesture

\section{Introduction}

In phonology, the terms 'tenseness' (tensing) and 'laxness' (laxing) are an important pair pertaining to the distinctive features of vowels. This distinction was first proposed by a Russian-American linguist, Roman Jakobson (cf. Chomsky and Halle, 
1968). According to Jones (1980), vowels may be differentiated by degrees of muscular tension, and therefore two classes of vowels, tense vowels and lax vowels, may be distinguished. Tense vowels are those which are assumed to require considerable muscular tension on the part of the tongue, whereas, lax vowels are those in the production of which the tongue is assumed to be more loose during their production.

A similar dichotomy, 'tenseness' - 'laxness', can also be observed in the bodygesture (B-G) behaviors. Much of our nonverbal behavior is characterized by change and movement during our various communicative activities which may also fit the above dichotomy quite easily.

On the basis of this distinction, the present author proposes to make a division between two body-gesture cultures, namely: the 'lax B-G cultures', and the 'tense B-G cultures', respectively.

Below, an attempt at their characterization is ventured.

\subsection{Two types of culture are distinguished with respect to human body-gesture (B-G) relationship}

1a) lax B-G cultures, and

1b) tense B-G cultures.

\subsection{Typology of Body-Gesture (B-G) cultures}

- The lax B-G culture is assumed to be unmarked (relaxed, casual, friendly, informal, non-ritual, common, etc.)

- The tense B-G culture is assumed to be marked (tense, non-casual, rigid, unfriendly, formal, ritual, restricted, ceremonial, etc.)

\subsection{Working hypotheses}

\section{Hypothesis no. 1 (H1):}

(H1a): The laxer the B-G system is, the less ritual (and more casual) a given communication act happens to be.

(H1b): The relationship "lax body posture + lax gesture" correlates with full spoken, profane (non-ritual) communication potential.

\section{Hypothesis no. 2 (H2):}

(H2a): The tenser the B-G system is, the more ritual a given communication act happens to be.

(H2b): The relationship "tense body posture + tense gesture" correlates with full spoken, ritual (non-profane) communication potential. 


\section{Iconic examples of both cultures and their discussion}

The present author is currently in the course of doing experimental and statistical work on the relationship of the two cultures, and the author's observations presented here are highly tentative and subject to further scrutiny.

\subsection{Instances of the typology of B-G cultures}

II.1a) A society designed to function in a lax body - gesture culture (e.g. Western open societies) is assumed to be educated to behave collectively as a system of generally lax communicative behaviors. The photos presented below (see Example $1 \mathrm{a}-1 \mathrm{~b})$ are indicative to the 'lax body-gesture culture' of the United States.

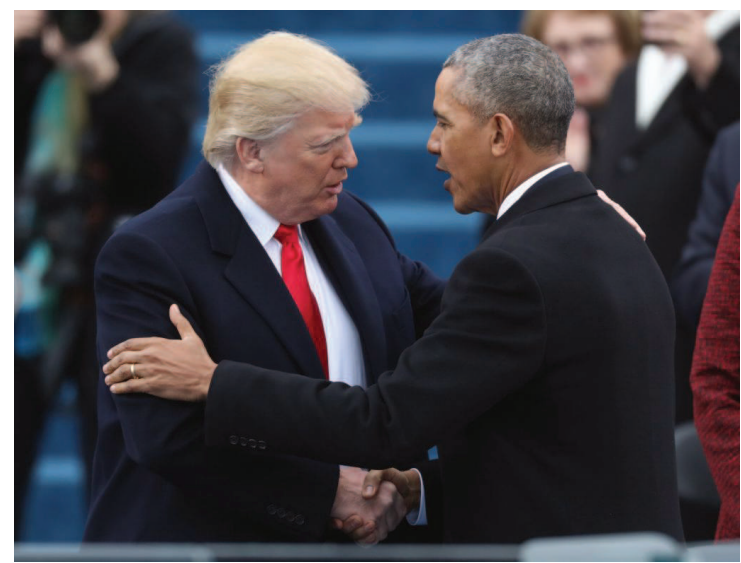

Example 1a.

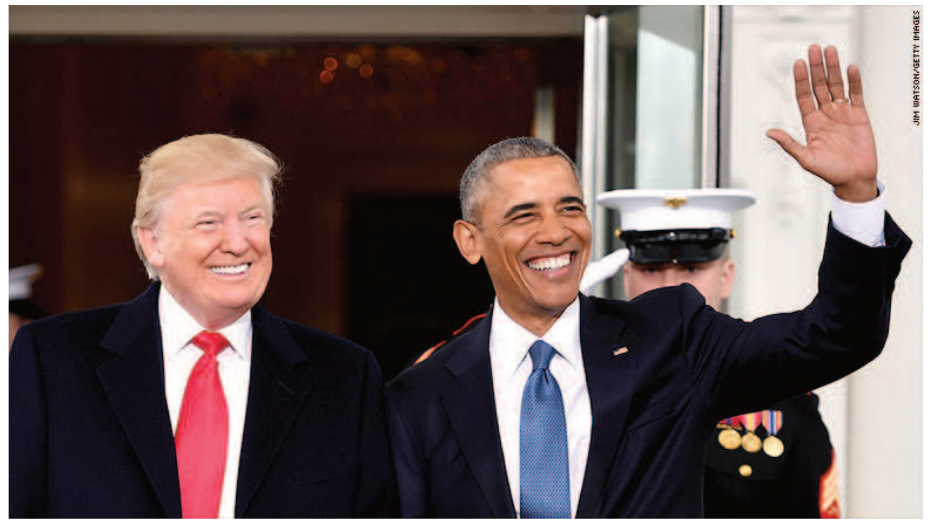

Example 1b. Examples 1a-1b: Obama meets Trump at the White House (in both photos, open gestures, positive facial expressions are used) (IS1). 
II.1b) A society designed to function in a tense body-gesture culture (e.g. North Korean culture) where a whole social group is assumed to be educated to behave collectively in a system of tense communicative behaviors. In such a society, the body-gesture complex is characterized by tense, non-casual, rigid, unfriendly, formal, ritual, restricted, ceremonial behaviors, as has been demonstrated in Example 2. One can also imagine that a tense body-gesture culture may be much smaller in size, though all the characteristics of such a tense culture are maintained. This can be seen in the communicative public behaviors on the part of autocratic mini societies. An example of such a mini society is the English Royal Court (see Example 3 below).

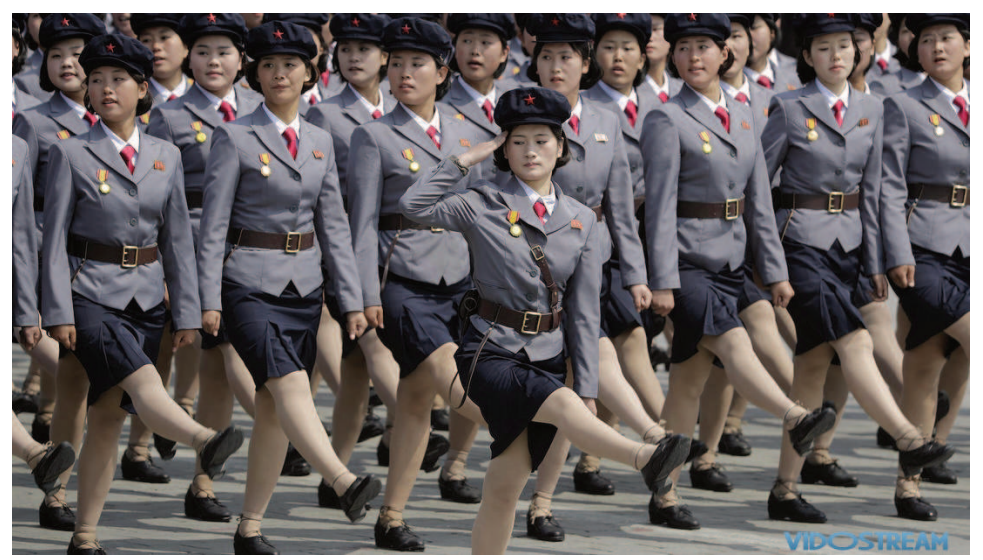

Example 2. North Korea Military Parade, April 15 $5^{\text {th }}, 2017$ (Women in uniforms march across Kim Il Sung Square during a military parade - "day of the sun" festival (tense body position, tight fists are demonstrably visible)) (IS2)

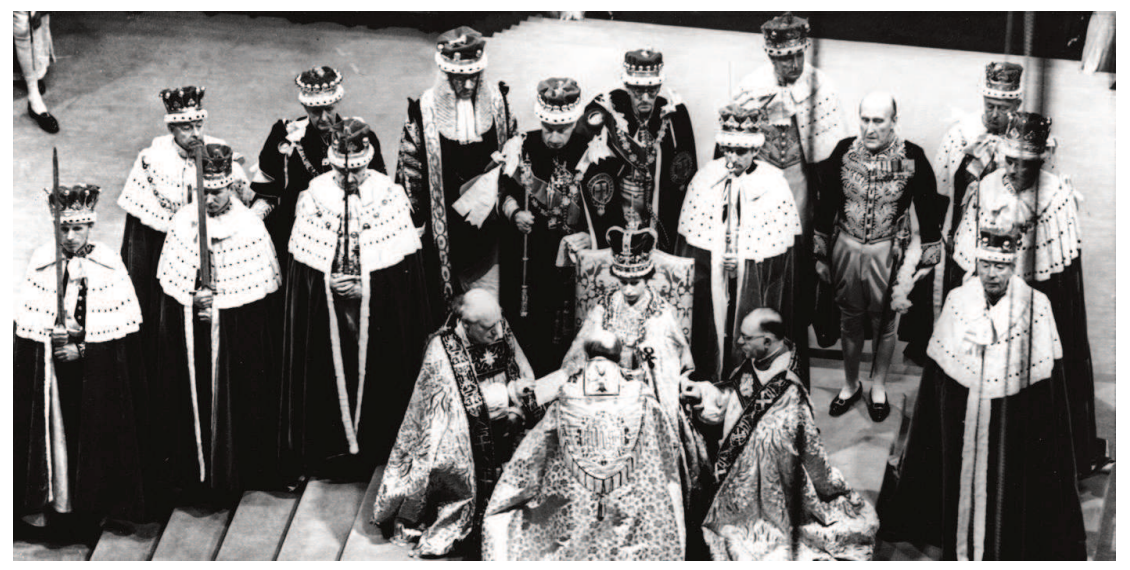

Example 3. The coronation ceremony of Queen Elizabeth II (kneeling body position, tight facial expressions of the persons involved can be noticed) (IS3) 


\subsection{Instances of the 'lax body posture + lax gesture' and 'tense body posture + tense gesture' combinations}

\section{A) Instances of the 'lax body posture + lax gesture'}

The 'lax body posture + lax gesture' system is characterized by the following features:

- Keeping the body upright,

- Keeping the head in neutral, erect position (head without bowing but also without looking down),

- Uncrossed arms,

- Uncrossed legs,

- Lying position.

When lying, the body may assume a great variety of shapes and positions. The following are the basic lying positions:

- Supine (lying on the back with the face up),

- Prone (lying on the chest with the face down),

- Lying on either side, with the body straight or bent/curled forward or backward.

The system may also involve:

- Sitting position. This human body position requires the buttocks resting on a more or less horizontal structure, such as a chair or the ground.

Laxness in the body and gesture complex is visible during a family conversation at a dinner table presented below (Example 4):

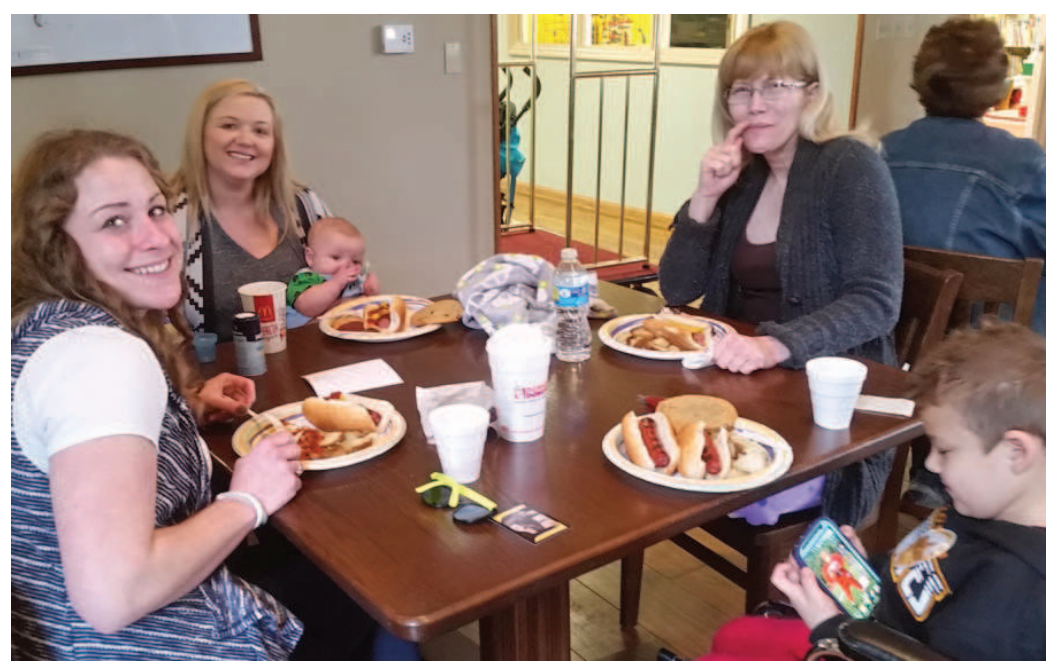

Example 4. Mothers with children at a dinner table (relaxed sitting position and positive facial expressions are visible) (IS4). 
The lax body posture and lax gesture are unmarked. They represent inertial, neutral and uncommitted behaviors of the communicators involved. Obviously, the lax body-gesture combinations are those which are used widely and therefore most preferably in the open public space.

\section{B) Instances of the 'tense body posture + tense gesture' combinations}

The 'tense body posture + tense gesture' system is characterized by the following features:

- Keeping the body in tension,

- The position of 'at attention', or 'standing at attention', is a military posture which involves the following general human positions:

- Standing upright with an assertive and correct posture in the 'chin up, chest out, shoulders back, stomach in' position,
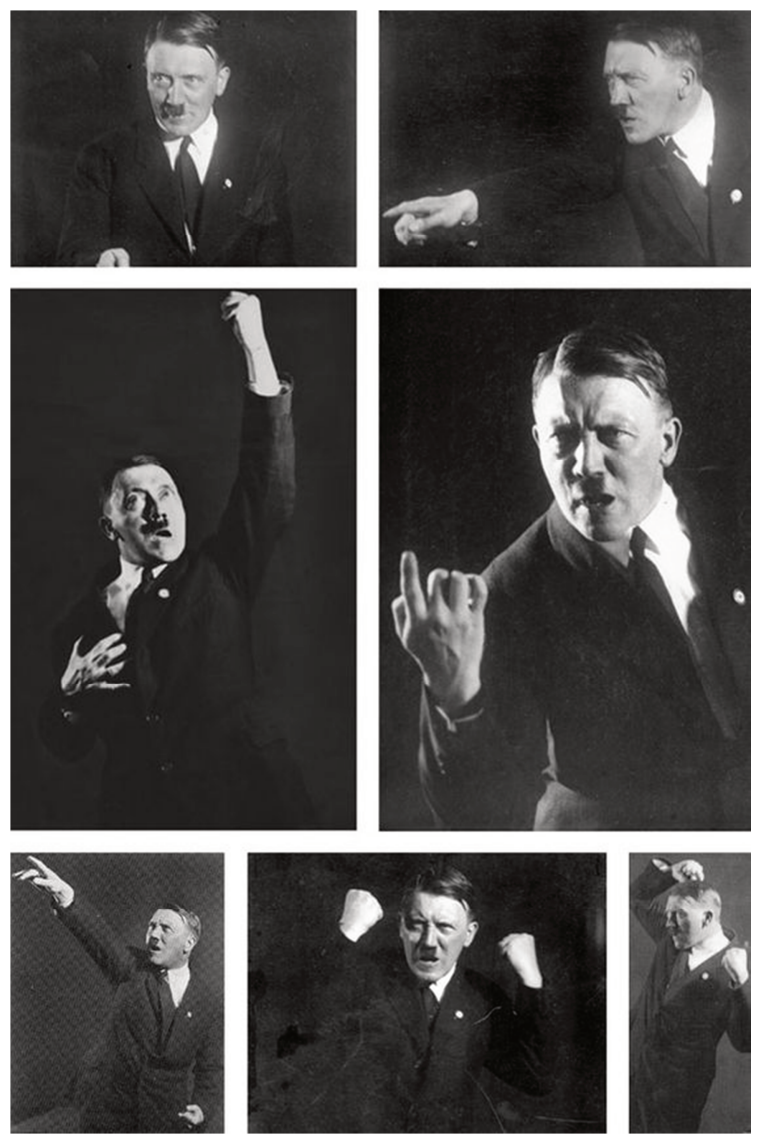

Example 5. Hitler rehearsing his speech in front of a mirror in 1925, photographed by Heinrich Hoffmann, Hitler's personal photographer (IS5) 
- Arms fixed at the side, thumb or middle finger parallel to trouser or skirt seam, depending on military drill specifics,

- Head and eyes locked in a fixed forward posture in the 'eyes front' position. Ideally, eyes unmoving and fixated on a distant object with blank facial expression.

- Keeping the heels together with the toes apart,

- Lack of abundant speech, facial or bodily movements, except when required by a military drill,

- Keeping the head hidden in shoulders,

- Crossed arms,

- Arms with clenched fists,

- Hands clutching the arms,

- Hands under the arm pits, and other variations of hands (hands in the air, fists in the air),

- Crossed legs,

- Kneeling.

Below, a series of photographs illustrate the tense body-gesture behaviors (Examples 5-6).

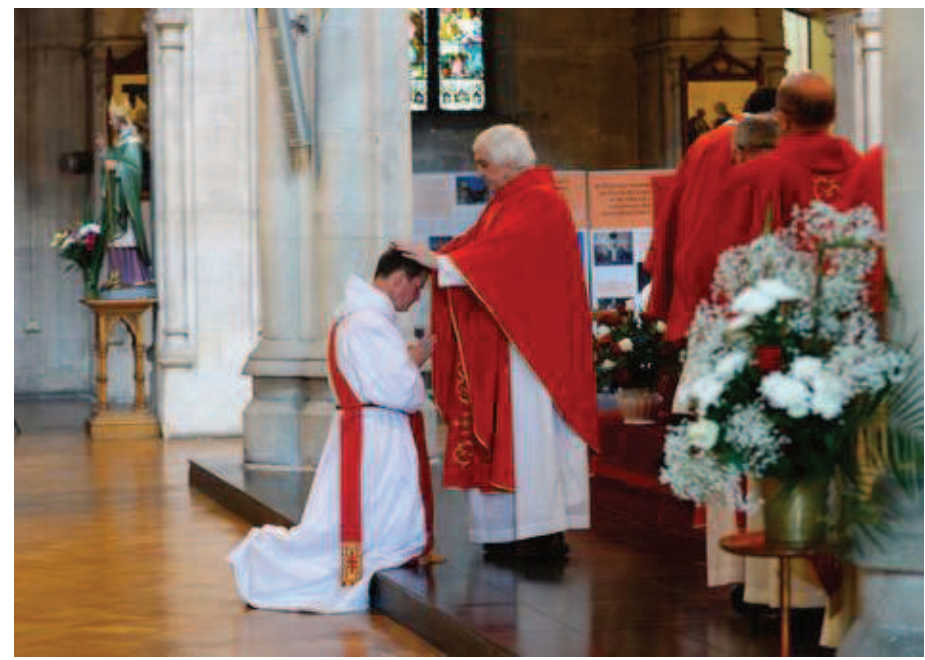

Example 6. The church ceremony - the rite of ordination of a priest (kneeling body position, hands with clenched fingers are visible) (IS6)

The 'tense body posture and tense gesture' combination is marked in the sense that it has to be evoked consciously. It represents a variety of tight, non-neutral, committed behaviors. 
The lax/tense body posture and lax/tense gesture make a clear opposition. Worth noting is the fact that lax/tense opposition is also connected with the type of clothing worn by the communicators (see the Queen's coronation, Example 3 and the photo above vs. Family at a dinner table, Example 4).

\section{Preliminary conclusions}

Although this project is still in the making and the outline presented above is very sketchy, it has already allowed the author to indicate clear differences between the two body-gesture systems with reference to their functioning.

The author of this article is convinced that the lax-tense distinction is a key distinction in accounting for observable differences in communicative behaviors used in the more or less open public space. The conclusions which may be offered at this point are the following:

1. The lax B-G system is more open and more commonly used in communication.

2. Being more open and more common, it is used in a wider variety of possibilities in communicative practice.

3. It is unmarked because it requires less energy and less conscious control/instruction on the part of the communicator(s). It is, therefore, regarded as less restrictive.

4. Being less restrictive, it is more universal (i.e. more open to all the communicators in a particular culture and language).

5. On the other hand, the tense B-G system is less open and less commonly used in communication.

6. Being less open and less common, it is used in a limited number of possibilities in communicative practice.

7. It is marked because it requires more energy and more conscious control/instruction on the part of the communicator(s). It is, therefore, regarded as more restrictive.

8. Being more restrictive, it is less universal (i.e. less open to all the communicators in a particular culture and language).

9. Every communicator is able to function in both types of cultures. Both cultures interpenetrate each other and they most naturally form an integral part of every communicator's linguistic-communicative competence. Obviously, they may differ in proportion.

10. Since the two types of communicative practice are postulated, unmarked vs. marked, the typology discussed above is assumed to have a clear pedagogical relevance in the sense that the communicative practices which characterize both types of cultures and B-G systems ought to be taught both to native and foreign language learners as parts of 'foreign language pedagogy'. 


\section{Bibliography}

Chomsky, N. and M. Halle. 1968. The sound pattern of English. New York: Harper and Row.

Hewes, G.W. 1955. "World distribution of certain postural habits". American Anthropologist 57. 231-244.

Hewes, G.W. 1957. "The anthropology of posture". Scientific American 196. 122-132.

Jackendoff, R. 2011. "What is the human language faculty?: Two views". Language 87. 586-624.

Jakobson, R. and M. Halle. 1956. Fundamentals of language. The Hague: Mouton and Co.

Jakobson, R., Fant, C.G.M. and M. Halle. 1951. Preliminaries to speech analysis. The distinctive features and their correlates. Cambridge, Mass.: MIT Press.

Jones, D. 1980. Everyman's English pronouncing dictionary. London: J. M. Dent and Sons, Ltd.

Puppel, J. 2014. Obecność i rola gestów rytualnych w przestrzeni publicznej. Analiza rzeźb sakralnych $w$ światyniach katolickich na terenie miasta Poznania $i$ wybranych okolic. Poznań: Wydawnictwo Naukowe UAM.

Puppel, J. 2017. "Rozwijanie kompetencji gesturalno-twarzowej transkomunikatora hybrydowego". In: Wiertlewska, J. (ed.). Język-Dydaktyka-Komunikacja. Toruń: Wydawnictwo Naukowe Uniwersytetu Mikołaja Kopernika. 79-92.

\section{Visual materials (Internet Sources, IS)}

IS1 - www.cnn.com [last access: 01 February 2018]

IS2 - http://www.global.vidostream.com/photos/unprecedented-photos/north-korea-celebrates-day-of-thesun-festival-4/36.html [last access: 01 February 2018]

IS3 - https://www.royal.uk/coronation [last access: 01 February 2018]

IS4 - https://rmhc-eiwi.org/get-involved/prepare-a-meal/ [last access: 01 February 2018]

IS5 - https://rarehistoricalphotos.com/hitler-rehearsing-speech-front-mirror-1925/ [last access: 08 February 2018]

IS6 - https://www.independent.ie/irish-news/news/former-600kayear-manchester-united-player-ordainedas-priest-35908903.html [last access 08 February 2018] 